\title{
Identifying learning style through eye tracking technology in adaptive learning systems
}

\author{
Inssaf El Guabassi ${ }^{1}$, Zakaria Bousalem ${ }^{2}$, Mohammed Al Achhab ${ }^{3}$, Ismail jellouli ${ }^{4}$, \\ Badr Eddine EL Mohajir ${ }^{5}$ \\ ${ }^{1,4,5}$ Faculty of Sciences, Abdelmalek Essaadi University, Moroco \\ ${ }^{2}$ Faculty of Science and Technologies, Hassan $1^{\text {st }}$ University, Morocco \\ ${ }^{3}$ National School of Applied Sciences, Abdelmalek Essaadi University, Moroco
}

\section{Article Info \\ Article history: \\ Received Jul 1, 2018 \\ Revised Apr 18, 2019 \\ Accepted Apr 25, 2019 \\ Keywords: \\ Adaptation \\ Adaptive learning \\ Eye tracking \\ Learning style detection

\begin{abstract}
Learner learning style represents a key principle and core value of the adaptive learning systems (ALS). Moreover, understanding individual learner learning styles is a very good condition for having the best services of resource adaptation. However, the majority of the ALS, which consider learning styles, use questionnaires in order to detect it, whereas this method has a various disadvantages, For example, it is unsuitable for some kinds of respondents, time-consuming to complete, it may be misunderstood by respondent, etc. In the present paper, we propose an approach for automatically detecting learning styles in ALS based on eye tracking technology, because it represents one of the most informative characteristics of gaze behavior. The experimental results showed a high relationship among the Felder-Silverman Learning Style and the eye movements recorded whilst learning.
\end{abstract}

Copyright (c) 2019 Institute of Advanced Engineering and Science. All rights reserved.

Corresponding Author:

Inssaf El Guabassi,

Faculty of Sciences,

Abdelmalek Essaadi University,

P.O.BOX 2121, Tetuan, 93000, Morocco.

Email: elguabassi@gmail.com

\section{INTRODUCTION}

Traditional education systems, which allow learner to learn independently without attending a classroom to meet the tutor, are unable to dynamically adapt to the learner's needs. Subsequently they are unable to increase the output of the learners. In this respect, recently the concept of adaptation has become an important issue of research in learning area; indeed, providing adaptivity in learning systems helps learners to make the intended learning outcomes via a personalized way.

This paper represents a continuation of our previous works carried out in the adaptive learning systems (ALS) [1-4], in which we provided adaptivity in ubiquitous learning systems based on learning styles of Felder-Silverman and learner context. However, a new adaptation problem has appeared, namely the automatic detection of learner learning styles.

Learning styles are increasingly incorporated to enhance learning outcomes for learners, and therefore many research approaches are done in education area, in fact, most researchers agree that learning styles play a key role in this area. One of the most widely used models of learning styles is the Felder-Silverman Index of Learning Styles (ILS). This model is extremely simple and, furthermore, the results are easy to interpret. However, at the same time the questionnaires in general suffer from several disadvantages, both theoretical and practical. For example, it is extremely impossible to record changing of learning styles because it is impossible to repeatedly ask learners to complete the questionnaire for time and cost concern. Fortunately, this problem can be solved using automatic detection of learning styles. 
Nowadays, it is possible to detect the learner learning styles via the biometric technologies. For example eye tracking, in fact, this technology has been extensively used in a large variety of applications such as diagnostics [5, 6], interaction and accessibility [7-11] and analytics [12-15]. This paper investigates and discusses an approach to provide adaptation in learning systems through eye tracking or gaze-tracking, this technology allows automatically understanding of individual learner learning preferences by recording of the point-of-gaze (POG).

The paper is structured as follows. After presenting the background, Section 3 concentrates on proposed approach. Section 4 describes our research methodology. Section 5 presents the experimental results. Finally, Section 6 displays the main conclusions and future research.

\section{BACKGROUND}

In this section we will discuss the three main terms to achieve our approach, these terms are: Firstly the learning objects (LO), secondly the learning styles and thirdly the eye tracking.

\subsection{Learning objects}

Learning object (LO) is a controversial concept, because unfortunately the scientific literature does not provide a single, concrete, and consensual definition for it, A learning object can be defined as "any entity, digital or non-digital, that may be used for learning, education or training" [16]. More simply, a learning object is "any digital resource that can be reused to support learning" [17]. Likewise, a learning object can be defined as "A digital self-contained and reusable entity, with a clear educational purpose, with at least three internal and editable components: content, learning activities and elements of context. The learning objects must have an external structure of information to facilitate their identification, storage and retrieval: the metadata."[18]. In short, we propose the following very global and working definition: A learning object is a digital learning resource.

On the other hand, the learning objects have the following key characteristics [19]: Is a part of learning materials - essentially consist of smaller units of learning, usually between 2 minutes and 15 minutes. Is self-contained - every learning object can be taken independently. Is Reusable (RLO = reusable learning object) - each learning object can be used in multiple learning material. Is Aggregated - LOs can be grouped into larger collections of content. Is tagged with metadata - each LO has descriptive information allowing. The media content of a learning object can include: video, text, audio, image, example, definition, illustration, exercise, diagram, simulation, assessment, etc.

\subsection{Learning styles}

Learners have different ways of learning; each learner has his own perception level, his own way of building and retaining knowledge. That's why a single style won't be appropriate for all learners. Therefore it is necessary to grasp his learning style first, in order to correctly choose the strategies and adapt the system to it. In our approach we chose the Felder-Silverman learning style, because it's Index of Learning Style (ILS) offers a practical and concrete approach to determine the dominant learning styles of each learner, plus the results of ILS can be easily connected to environments. According to FelderSilverman Learning Style Model (FSLSM) [20], learners are characterized by their preferences in four dimensions as shown in Table 1:

Table 1. FSLSM Learning style dimensions

\begin{tabular}{lll}
\hline Dimensions & Style & Keywords Groups \\
\hline Processing & Active & Prefers to try and experience new concepts \\
Reflective & $\begin{array}{l}\text { Likes to think about things before taking action } \\
\text { Sensing } \\
\text { Intuitive }\end{array}$ & $\begin{array}{l}\text { Likes to use methods established practically and carefully } \\
\text { Tends to work quickly and be innovative and usually can manipulate abstract and mathematical } \\
\text { concepts }\end{array}$ \\
& Visual & $\begin{array}{l}\text { Better assimilation of new information through graphics, demonstrations, diagrams, graphs, etc. } \\
\text { Better assimilation through vocalized and written words }\end{array}$ \\
Receiving & $\begin{array}{l}\text { Verbal } \\
\text { Sequential } \\
\text { Understanding }\end{array}$ & $\begin{array}{l}\text { Prefers to assimilate new knowledge linearly and logically } \\
\text { Prefers a systematic approach }\end{array}$ \\
\hline
\end{tabular}

\subsection{Eye tracking}

In the simplest terms, Eye tracking or gaze-tracking is a technology of recording, study, and measurement of either the coordinates of a human gaze point. In general, gaze refers to where your eyes are focused and therefore know exactly your real preferences. The device used to determine the direction of the 
point gaze is called eye-tracker. The Eye tracking technology has been used in many scientific studies such as neuroscience studies, marketing and e-commerce research, cognitive science, psychology, car driving, medical research, etc.

An example of high performing eye tracking system is depicted on Figure 1. Three vital parts of this system are [21]:

1. Custom-designed sensors : It consists of custom designed infrared projectors, customized image sensors, optics and custom processing with embedded algorithms

2. Advanced algorithms : It interprets the image stream generated by the sensors

3. User-oriented applications : An layer to activate the many different ways the technology can be used

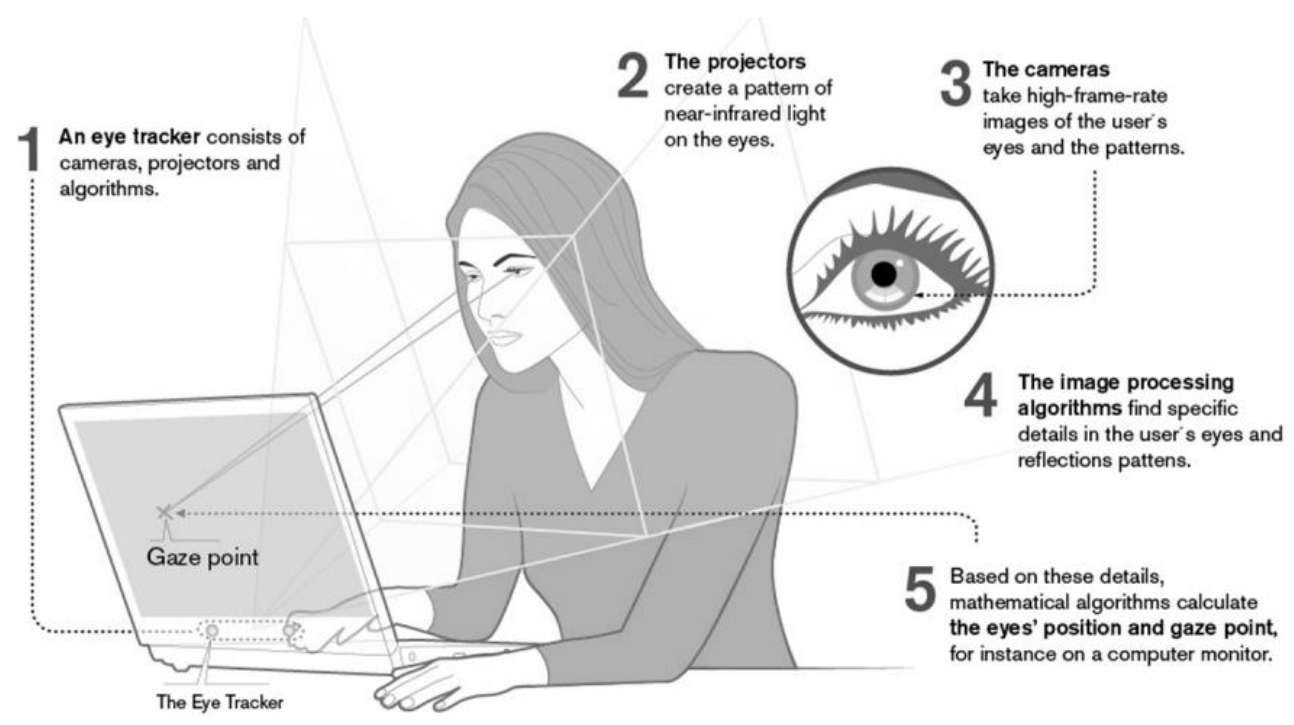

Figure 1. How the eye tracker works [21]

\section{PROPOSED APPROACH}

Each learner conceives and perceives learning differently. They have different strengths and weaknesses. There are several learning styles, and therefore we must create a course that adapts to each learner. In this way, the individual preferences of the learners are respected, and consequently they can have better results. Learning style identification is traditionally done by using a questionnaire. Beside the use of the questionnaires, they are a useful method to investigate. However, they have a number of major disadvantages as well:

1. May be unsuitable for some kinds of respondents

2. There is the danger of questionnaire fatigue

3. May be ignore certain questions by respondent

4. May be misunderstood by respondent

5. Time-consuming to complete

6. Etc.

On the other hand, system cannot record changing of learning styles because it is impossible to repeatedly ask learners to complete the questionnaire. Recent studies demonstrate that it is possible to identify the most preferred learning styles, though biometric technologies in particular mouse movements, accelerometer and eye tracking, etc.

In this present work we propose an approach to provide adaptation in learning systems through eye tracking technology, this latter allows automatically detect the preferred learning style of each learner. Our paper will present the results of the baseline study conducted to identify learner learning style based on the Felder-Silverman Learning Style Model (FSLSM) [20]. This paper consists of three main processes: The learning objects are firstly described. Next, the learning styles are detected. Finally, the adaptation is provided. More details on processes will be given below in the Research Methodology section. 


\section{RESEARCH METHODOLOGY}

This section describes the three phases of research methodology which include: describing learning objects, detecting learning styles, and providing adaptivity.

\subsection{Describing learning objects}

This phase consists essentially to give the user access to a learning object, based on an indication of their content and / or their nature (format, type), and consequently the main purpose is to enable learners to seek and use learning objects, and to enable them to compile learning objects for each individual learner. To describe our learning objects, we used the international standard LOM [22], which proposes a metadata model description associated with pedagogical objects whatever they are digital or not. In more general terms, The IEEE's Learning Object Metadata (LOM), used to describe a learning object used to create of well structured description of learning resources, to support the reusability of learning objects, to facilitate their interoperability, and to aid discoverability, usually in the context of adaptive learning systems (ALS). A representation of the hierarchy of elements in the LOM data model is shown in Figure 2.

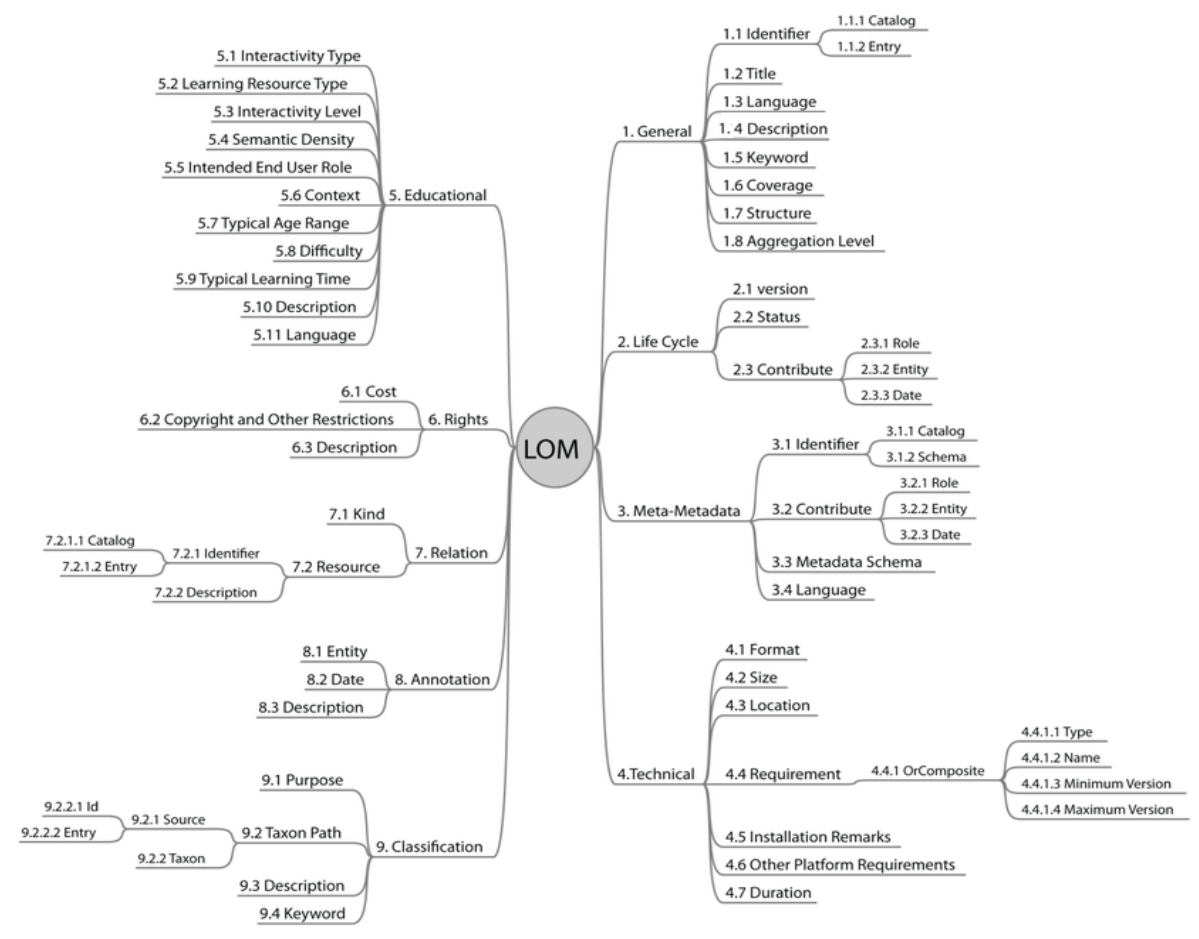

Figure 2. The learning object metadata scheme

The need for adaptation of learning objects to the needs of the learner, we added an element to technical category of the LOM data model. Of course, this element is the learning styles according to FelderSilverman Learning Style Model (FSLSM) [20], but our focus will be especially on the Visual / Verbal dimension. The learning objects in our system are labeled as represented in Table 2. This description is based on the theoretical descriptions about leaning styles' characteristics of FSLSM.

Table 2. Labels of our learning objects

\begin{tabular}{ll}
\hline Visual & Verbal \\
\hline Image & Audio \\
Diagram & Text \\
Video & \\
Board & \\
Animation & \\
Graph & \\
Simulation & \\
Slideshow & \\
Hypertext & \\
Conference video & \\
\hline
\end{tabular}


After seeing our learning object design, in the next section we will present how we can automatically estimate learners' learning styles?

\subsection{Detecting learning styles}

It is very important to introduce the adaptation to the online learning system by developing the mechanism to identify the learning styles to comply with the requirements of FSLSM [19]. However the problematic are:

a. It is impossible to repeatedly ask each learner to complete the questionnaire for time and cost concern, whereas the system has to face the challenge of recording the changing of learning style during the learning.

b. The questionnaires have a number of major disadvantages in general, as shown previously.

In very general terms, an automatic method for tracking learning styles is the essential part of an efficient massive ALS.

In the present study, we used an eye gaze recorder to record the time that the participants gazed at text-based or graphic-based learning objects. Therefore, we compared the results with the results obtained through the questionnaire of the FSLSM. In this first study, we focused especially on the Visual / Verbal dimension.

The major steps to achieve the comparison to find the relationship among the Felder-Silverman Learning Style and the eye tracking are:

a. The learner complete the Felder-Silverman Index of Learning Styles (ILS) questionnaire to determine whether he/she is visual or verbal

b. The system proposes to the learner a learning object which is displayed in text and graphic form. For that purpose, the screen is divided into two distinct parts. One half of the screen offered textual representation of learning object whilst the second half of the screen offered graphical representation of the same learning object.

c. Eye tracking technology is used in this step to determine the point-of-gaze (POG) of the learner on the screen.

d. Generation of the results of eye tracking experiment

e. Comparison of the results of the Felder-Silverman Index of Learning Styles (ILS) questionnaire and the results obtained via eye tracking technology.

The results of this experiment will be presented and discussed in Results and Discussion section. In the next section, we will see how to provide adaptation in the online learning system by the use of learning objects and learner learning styles?

\subsection{Providing adaptivity}

After describing the learning objects and detecting the learner learning styles, we are now committed to providing learners with an adapted course according to his/her Individual learning preferences. The adaptation can be explained as: The learner profile is represented as vector, and also each learning objects in the course is represented as a vector, and then the learner interest prediction is achieved by calculating similarity value between the learner profile vector and the learning objects vector.

There are many similarity measures available, but the most widely-used measure in the field of information research is the cosine similarity.

Given two vectors, $V_{L O}=\left\langle L O_{L L}, L O_{P}, L O_{L g}, L O_{L S}\right\rangle$ describing the learning objects and the vector $V_{L P}=\left\langle L P_{L L}, L P_{P}, L P_{L g}, L P_{L S}\right\rangle$ describing the learner profile, Where:

$\mathbf{L L}$ : Represents the level (e.g. Beginner, Intermediate, or Expert).

P : Represents the plateform (e.g. Computer, mobile, tablets, etc.).

Lg : Represents the language (e.g. Arabic, French, English, etc.).

LS : Represents the learning styles (e.g. Visual or Verbal)

$$
\cos \left(V_{L O}, V_{L P}\right)=\frac{\sum_{i=1}^{4} L O_{i} \sum_{i=1}^{4} L P_{i}}{\sqrt{\sum_{i=1}^{4} L O_{i}^{2}} \cdot \sqrt{\sum_{i=1}^{4} L P_{i}^{2}}}
$$

When the resulting score is 1 the learning object LOi and the learning profile LPi are identical, and 0 if there is nothing in common between them. The question now being asked is what are the next steps after calculating similarity value? Of course, there are many steps along the road to ensuring adaptation in learning 
systems for example: Arrangement of the different selected learning objects, but we will explain them in other paper because we focused in this work on identifying learning styles automatically. The results and discussion section answers one main question: Can we understand learners' learning styles by eye tracking technology in adaptive learning systems (ALS)?

\section{EXPERIMENT}

\subsection{Participants}

Multiple participants took part in this experiment. However, due to problem related to calibration, we got seven valid data ( 2 male and 5 female). Their average age was 30.5 years old and most of them were from graduate studies. Their varied from physics, medicine, and computer science. Two of them had normal vision and the other had corrected to normal vision (they were wearing glasses).

\subsection{Procedure}

The whole experiment lasted approximately 20-30 minutes, depending on participant's reading speed, reading comprehension and calibration process. Experiment procedure is shown in Figure 3 . The first section of the experiment started with the ILS questionnaire. Then, after finishing this part, the participant is asked to calibrate the eye-tracker. Afterwards, he is prayed to learn the NLP concept, once the calibration is qualified. In these moments, the gaze tracking system is recorded the participant's eye movements. Finally, the results are generated and showed.

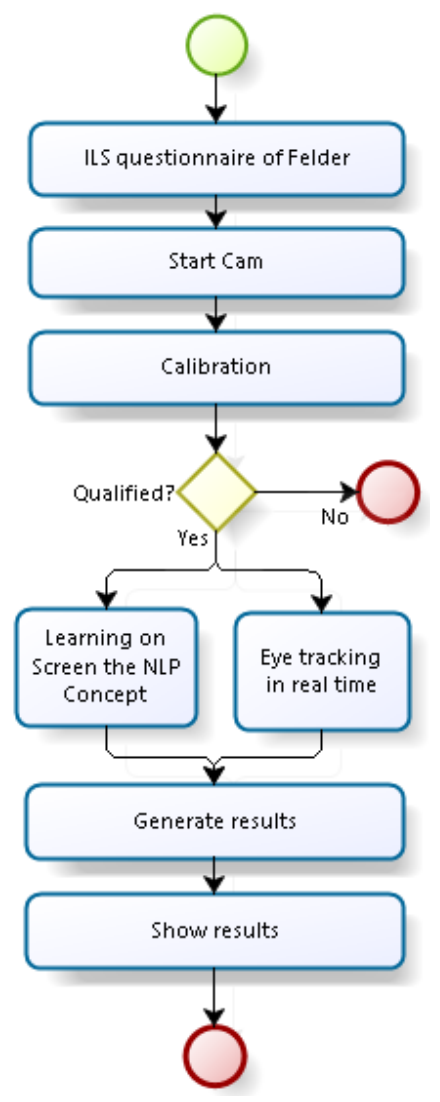

Figure 3. Experiment procedure

\subsection{Equipment and setting}

We recorded eye movements from participants using a GazeRecorder [23] gaze tracking system, which is characterized by:

1. Automatically records using ordinary WebCam

2. No hardware required - only webcam and computer

3. No direct physical contact with users for gaze tracking 
4. Eye tracking in real time

5. Gaze tracking usability testing

6. Create experiments with a single click

7. Heatmap surface is generated dynamically with adaptive time window

GazeRecorder has a number of different configuration parameters that control eye tracking, as indicated in Table 3.

Table 3. Configuration parameters

\begin{tabular}{ll}
\hline Measure & Values \\
\hline Time window & $500 \mathrm{~ms}$ \\
Gaze Plot Size & $12 \%$ \\
Adaptive extend time window during static screen & Yes \\
Extend time window when screen appearance & $5 \%$ \\
change less than & \\
Show mouse cursor & No \\
Show face & No \\
(FOV) cam field of view vercical & 42 deg \\
WebCam location & \\
Resolution & $640 * 480$ \\
Calibration Type & 5 points \\
Pupil distans & $5.2 \mathrm{~m}$ \\
\hline
\end{tabular}

\subsection{Interface description}

The experimental validation of our approach is done by presenting the concept of Neuro-linguistic programming (NLP) to the participants. Of course, they have no prior information or knowledge about this concept. The screen is divided into two distinct parts as shown in Figure 4. One half of the screen offered textual representation of NLP whilst the second half of the screen offered her graphical representation.

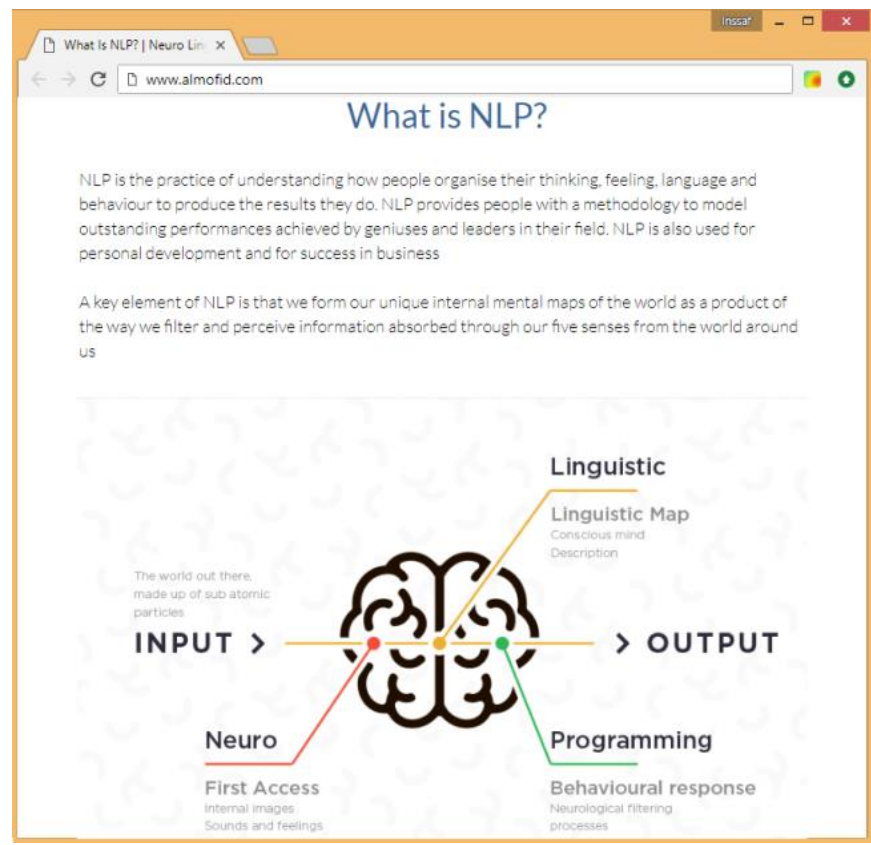

Figure 4. Interface representation

\subsection{Results}

GazeRecorder [23] gaze tracking system uses an ordinary WebCam to track and record what part of the screen the participant was looking at, and then generated a smooth heatmap which is a graphical representation of this data. There are several different advantages of heatmap. Indeed it is simple, easy to use 
and the results are easy to interpret. In our case, the heatmaps indicate where the learner had viewed the screen? He had looked at text and/or graphics?

The heatmaps for each user indicate that there is a significant difference between visual and verbal learners. Indeed the results demonstrated that the verbal learners according to ILS questionnaire of the Felder-Silverman, spent a majority of their time looking at the textual part of the screen as illustrated in Figure 5(a). Moreover the visual learners spend more time looking at the graphical part of the screen as shown in Figure 5 (b).

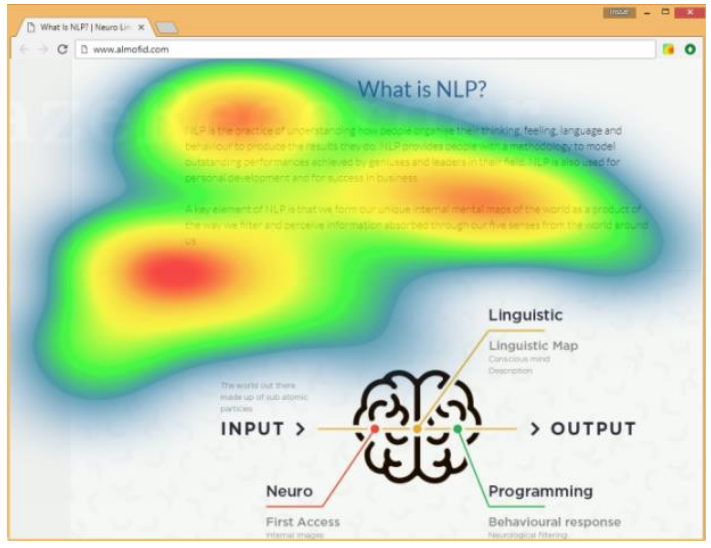

(a)

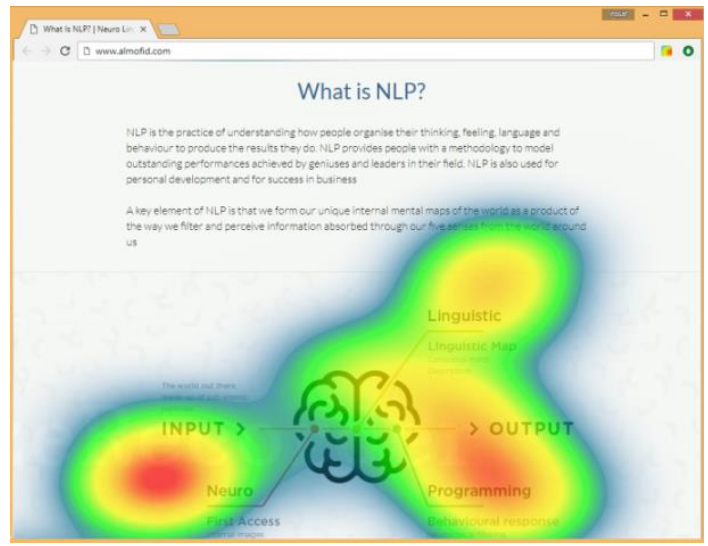

(b)

Figure 5. Verbal and visual learner heatmap

\section{CONCLUSION AND FUTURE WORK}

The length of a fixation is one of the most important characteristics to understand human behavior, in fact, eye movement recording during reading is very important information in adaptive learning systems (ALS). An approach for Identifying learning style through eye tracking technology in ALS has been presented which addresses the need to (1) Describe learning objects in adapted way in different kind of courses, (2) Provide an automated method for detecting learning styles based on eye tracking technology, and (3) Provide an ALS using learning styles and learning objects. We are investigating several extensions to this work:

a. Implementing the proposed approach on multiple computing platforms (cross-platform)

b. Including others biometric technologies such as mouse movements

c. Completing the Providing Adaptivity subsection

\section{REFERENCES}

[1] El Guabassi, I., Al Achhab, M., Jellouli, I., El Mohajir, B. E., "Recommender system for ubiquitous learning based on decision tree," In Information Science and Technology (CiSt), 2016 4th IEEE International Colloquium on, IEEE, Oct 2016, pp. 535-540.

[2] El Guabassi, I., Al Achhab, M., Jellouli, I., Mohajir, B. E. E., "Context-Aware Recommender Systems for Learning," International Journal of Information Science and Technology, vol. 1(1), pp. 17-25, 2018.

[3] Guabassi, I. E., Achhab, M. A., Jellouli, I., Mohajir, B. E. E., "Towards adaptive ubiquitous learning systems," International Journal of Knowledge and Learning, vol. 11(1), pp. 3-23, 2016.

[4] El Guabassi, I., Bousalem, Z., Al Achhab, M., JELLOULI, I., Mohajir, B. E. E., "Personalized adaptive content system for context-aware ubiquitous learning,"Procedia Computer Science, vol. 127, pp. 444-453, 2018.

[5] Alamudun, F., Yoon, H. J., Hudson, K. B., Morin-Ducote, G., Hammond, T., Tourassi, G. D., "Fractal analysis of visual search activity for mass detection during mammographic screening," Medical physics, vol. 44(3), pp. 832-846, 2017.

[6] Holmqvist K., Nyström M., Andersson R., Dewhurst R., Jarodzka H., Van de Weijer J., "Eye tracking: A comprehensive guide to methods and measures," OUP Oxford, 2011.

[7] Duchowski A. T., "Eye tracking methodology," Theory and practice, vol. 328, 2007.

[8] Vijay Rajanna, "Gaze Typing Through Foot-Operated Wearable Device," In Proceedings of the 18th International ACM SIGACCESS Conference on Computers and Accessibility (ASSETS '16), ACM, New York, NY, USA, 2016, pp. 345-346. 
[9] Rajanna V., and Hammond T., "GAWSCHI: gaze-augmented, wearable-supplemented computer-human interaction," In Proceedings of the Ninth Biennial ACM Symposium on Eye Tracking Research \& Applications, ACM, Mar. 2016, pp. 233-236.

[10] Rajanna V., Malla A. H., Bhagat R. A., Hammond T., "DyGazePass: A gaze gesture-based dynamic authentication system to counter shoulder surfing and video analysis attacks," In Identity, Security, and Behavior Analysis (ISBA), 2018 IEEE 4th International Conference, on IEEE, Jan 2018, pp. 1-8.

[11] Rajanna V., Polsley S., Taele P., Hammond T, "A gaze gesture-based user authentication system to counter shoulder-surfing attacks," In Proceedings of the 2017 CHI Conference Extended Abstracts on Human Factors in Computing Systems, ACM, 2017, pp. 1978-1986.

[12] Alamudun F. T., Hammond T., Yoon H. J., Tourassi G. D., "Geometry and Gesture-Based Features from Saccadic Eye-Movement as a Biometric in Radiology," In International Conference on Augmented Cognition, Springer, Cham, Jul 2017, pp. 123-138.

[13] Becker W., and Jürgens R., "An analysis of the saccadic system by means of double step stimuli," Vision research, vol. 19(9), pp. 967-983, 1979.

[14] Kaul P., Rajanna V., Hammond T., "Exploring users' perceived activities in a sketch-based intelligent tutoring system through eye movement data," In Proceedings of the ACM Symposium on Applied Perception, ACM, Jul 2016, pp. 134-134.

[15] Rayner K., Carlson M., Frazier L., "The interaction of syntax and semantics during sentence processing: Eye movements in the analysis of semantically biased sentences,"Journal of verbal learning and verbal behavior, vol. 22(3), pp. 358-374, 1983.

[16] Learning Technology Standards Committee, "Draft Standard for Learning Object Metadata," IEEE Standard 1484.12.1, New York: Institute of Electrical and Electronics Engineers, 2002.

[17] Wiley David A, "Connecting Learning Objects to Instructional Design Theory: A Definition, A Metaphor, and A Taxonomy", in Wiley, David A. (DOC), The Instructional Use of Learning Objects: Online Version, 2002.

[18] Rehak, Daniel R.; Mason, Robin, "Engaging with the Learning Object Economy", in Littlejohn, Allison, Reusing Online Resources: A Sustainable Approach to E-Learning, London: Kogan Page, pp. 22-30, 2003.

[19] Beck, Robert J., "What Are Learning Objects?," Learning Objects, Center for International Education, University of Wisconsin-Milwaukee, retrieved apr 292008.

[20] Felder, R. M., Silverman, L. K, "Learning and teaching styles in engineering education. Engineering education," Journal of Engineering Education, vol. 78(7), pp. 674-681, 1988.

[21] Babenko A., Kotenko A., "The Eye Tribe,” Doctoral dissertation, Sumy State University, 2016.

[22] IEEE Learning Technology Standards Committee, IEEE LOM working draft 6.1., 2001.

[23] Deja, Szymon, GazeRecorder. Available: https: //www. facebook.com / gazerecorder/, 2016. 